\title{
Development of a Non-Formal Education Process to Promote the Awareness in Living Together with Care in Urban Communities: A Case Study of Bann Krua Nua Community
}

\author{
Kittikantaphong Sribuawnam ${ }^{1}$, Weerachat Soopunyo ${ }^{2}$, Kultida Chancharoen ${ }^{3}$ \\ 1,2,3 Chulalongkorn University, Thailand \\ 1eak_ku27@hotmail.com
}

\begin{abstract}
The aims of this research were to 1) development of a non-formal education process to promote the awareness in living together with care in urban communities, and 2) propose guidelines for raising awareness in living together with care in urban communities with the non-formal education process. Participatory action research (PAR) was conducted in Ban Krua Nua, Thanon Phetchaburi, Ratchathewi, Bangkok. Research participants comprised community leaders, community committees and community residents of Ban Krua Nuea. Data were collected by observation, interview and group discussion. Research instrument's included interview form, data recording form and the researcher. Research data were analyzed by ways of content analysis. The findings were as follows; 1) A non-formal education process to promote the awareness in living together with care in urban community of Ban Krua Nua community consisted of 5 process namely, 1) perceive the problems 2) planning 3) implementation, 4) conclusions and 5) reflection and 2) The propose guidelines for raising awareness in living together with care in urban communities with the non-formal education process derived from the area and jointly developed with the Ban Krua Nua community and the group discussion which consisted of 8 components as follows; 1) "Participation" included participation in sharing, thinking together, doing and creating together. 2) " Happiness" included willingness to participate in activities and happy to participate in the activity. 3) "Learning" included learning by itself learn others learn community as well as learning to live together in society. 4) "Conservation" included love and good will, love and care for the people in the community, maintain the traditions and culture of the community to continue. 5) " Creative" included the initiative to create activities, know how to solve problems in order to develop the community to be progressive and sustainable. 6) "Coordination" included coordination and having unity. 7) "Acceptation" included accepting and learning each other accepting and listening to others' opinions and 8) " Knowledge" included knowing the role and function of yourself, knowing the traditions, laws and knowing the changes of the world.
\end{abstract}

Keywords

Non-Formal Education Process, Living Together with Care, Urban Communities

Article Received: 10 August 2020, Revised: 25 October 2020, Accepted: 18 November 2020

\section{Introduction}

In the past, the way of life of the people in the community would have been kinship or well-acquainted with each other until they were close relatives. Therefore, helping each other with generosity is spreading out to each other, but nowadays each person has more responsibilities. Therefore, they rarely had time to meet and talk. In addition, some people in the community have migrated to other places and someone from other places has arrived again. It causes much more distance from each other than in the past (Daranee Thawinphiphatkul, 1998) [1] related to Jintana Sujjanan (2013) [2], who spoke about the way of life of the people in the community that has changed, there are major reasons as follows: 1) increase in population causing the community to expand as a result, the way of life of the people in the community has changed until the problem of slum communities. 2) The technological development, when the country is prosperous, technology is used to facilitate. Therefore, the way of life of the people in the community has changed as well. In current situation, harvesting vehicles are used instead of human labor. Telephones were used for general communicated with each other. 3) Economic development, as a result, it has changed in various fields including production, employment, such as in the past, focusing on production for subsistence in order to have food and use within the family, community, but now it has become a production for trade and export, and 4) culture from other places due to the convenience and speed of communication, it has rapidly adopted cultures from other places such as culture, dress, expression and eating. In addition, Jintana Sujjanan (2013) [3] said that Thai lifestyle has changed, linking Thai way of life with foreign cultures, causing world cultures to spread into Thailand through globalization and cyber fast. This is an important factor affecting Thai culture in terms of way of life, attitudes, beliefs, interpersonal relationships. Learning process and consumption behavior Thai people seek happiness and create a more personal identity. There is a tendency to build social networks through the cyber world, creating many contemporary sub-cultures, forms of integration of individuals who are interested in the same subject, but cannot express Thai identity clearly.

Study Center and Peace Development (2007) [4] states that when society consists of diverse groups of people inevitably creates problems or conflicts due to the diversity of different groups of people. These conflicts range from the smallest to the largest. The smallest level is the individual, because everyone has internal conflicts, for example, in a decision to take a certain action, it is up to the individual whether he chooses to act or not. Later, it is the family with the smallest social unit, but it is the most important is that the family will consist of the differences of each member in gender, age, education, as well as the status and roles in the family. 
Finally, the largest unit such as community, society, country or international as at the Office of Women's and Family Activities the Ministry of Labour and Social Welfare (2009) [5] analyses the current situation of Thai families that they are facing three major problems: 1) The family structure and function have changed, resulting in the family being unable to function properly. This can be seen from the smaller family size. More women served as the head of the family. Families have more parents raising their children alone. The elderly is abandoned more homeless or homeless children. Family members are unable to fulfil their duties, for example, their spouses do not act as a good partner. Parents do not train, instruct and raise their children, but instead pushes the elderly or the nursery to act instead. Family members do not have time to be ready to engage in activities together. 2) The deterioration of family relationships. This can be seen from the increasing divorce rate. There is an increase in domestic violence and sexual violence against children and women, lack of good communication and learning to live together, and 3) lack of morality, ethics and quality, inability to be self-reliant. There is competition that take advantage of selfishness and consumerism spending more than you have to have debt Therefore, it can be seen that from the family level, community, society, country, all have to face the problem of differences and conflicts. It is the country's prosperity center, that is, a center for government administration, trade, banking and the largest industrial area. There are various basic services. The economy and society are at a higher standard than any other city. Therefore, it has a high economic attractiveness. As a result, most regions and cities are under the influence of Bangkok. It is also an attraction for people from rural areas struggling to migrate to Bangkok. From the current social phenomenon, it was found that the progress of urban communities causing the migration of the population in rural areas, there is more to urban areas. When the urban population density increases, there were changes in the economy, society and various problems which corresponds to the era of Srisak Wallipodom (2558) [7] that said Bangkok today is full of new vehicles and buildings. There are a number of people who flock to make a living in the capital until the overwhelming population of the city. It only increases from the aforementioned problems, the livelihood of Bangkok residents is poor, and lack of humanity because everyone has become selfish. The reason for this is because society in Bangkok lacks a community [8]. Saowapa Pornsiripongse and others (2007) [9] conducted a preliminary study on the Baan Krua Nuea community found problems in the community of Ban Khrua Nuea, including 1) in the community there was a split, and lack of unity, 2) people in the community have not received the necessary information in various fields, and community activities community actions, 3) People in the community still cooperate in meetings disseminating news of lesser communities, 4) more immigrants from other provinces due to their urban centers, and 5) have environmental problems (Garbage/sewage) and crime problems.

From the aforementioned problems, it is imperative that we find ways to help raise awareness of coexistence among the people living in the community. Most of the relevant research studies focus on social, cultural and economic problems, but no research has yet studied supportive coexistence. Therefore, the researcher is interested in studying the coexistence of the Ban Krua Nuea community by applying a non-school education process to raise awareness of the coexistence of the Ban Krua Nuea community so that able to coexist with others in society in a normal way, bringing peace to oneself, others and the country, as non-formal education has its objectives and goals to provide people with the basic knowledge necessary to lead to use in life to have knowledge of applying in the profession. Receive knowledge of news that is up-to-date, morally, and morally able to coexist with others in society normally. It can face problems, think and analyze the situation, able to seek knowledge and choose to receive knowledge from various sources, used to improve the quality of life and solve problems appropriately as well as being able to adapt to the constantly changing social and environmental conditions.

\section{Research Objectives}

The purposes of this research were 1)to develop of a nonformal education process to promote the awareness in living together with care in urban communities, and 2) propose guidelines for raising awareness in living together with care in urban communities with the non-formal education process.

\section{Research Conceptual Framework}

This research uses the concept of lifelong education and the concept of living together as the main concept in this research.

Concept of Lifelong Learning (Livelong Learning) Lifelong Education Institute (2008) presents education that leads to the concept of lifelong education. Education is a lifelong process of mastering the intrinsic nature of understanding human nature. Education should open the way for a person to become the best and perfect human being possible.

The concept of living together (UNESCO), the United Nations Educational, Scientific and Cultural Organization (UNESCO), describes an approach to educational management for the 21st century. The "four pillars of education" that are the core of education management in the 21 st century consist of four aspects of learning: Learning to know, Learning to do, Learning to live together, and Learning to live be.

\section{Research Method}

\section{A. Target Group and Research Process}

This research was action research with applied Participation Action Research (PAR), which Kemmis and Mctaggart (1990) [10] and Knowles, Malclom S. (1984). [11] defined action research as a research that reflects performance beginning with operational planning, observation and reflection. It is research that requires a participant in the process of reflecting on the practice in order to make corrections, improvements and developments for the better the participatory action research is divided into 4 steps as follows: 
1) The planning phase (Plan) begins with exploring the problem that needs to be solved. Researchers and stakeholders jointly plan and explore the state of the problem. What is the problem that needs to be solved? Who is the problem related to? How to fix it? What corrections need to be fixed? Analyze problem conditions as a guideline for systematically finding the structure of the problem review aspects of the problem, discuss a wide range of problems with research participants or other stakeholders. This will make the problem more clearly visible.

2) Action phase is the concept of planning activities to implement. When doing action, a critical analysis is required, accompanied by a list of stakeholders which will return information. How well is the planned plan performed? What are some obstacles in this practice? Therefore, the planned program may be flexible.

3) Observe, while the research is carried out according to the planned activities, observation must be followed and write down all the events that are expected and not expected by what is observed. Operating process and the results of the operation which while the research operation is being carried out in conjunction with the observation results appropriate techniques should also be used to help gather information.

4) The Reflect phase is the final stage of the operational research cycle. It is the assessment or examination of a process, problem or obstacle to the operation for which the researcher and the relevant person must examine the process, problem or obstacle to the operation through discussion of the issues that will be guided by the development of the action steps and form the basis of information that leads to improvement and planning of further action.

The scope of the research was as follows: The target groups that participate in the development of non-formal education processes to raise awareness of a supportive coexistence in urban communities are community leaders, and community committees of 20 people in Ban Krua Nuea community and target groups who attended group meetings to propose guidelines for living together in the urban community with the non-school education process, including experts in nonschool education, religious leader, community development leader, Ratchathewi District, Baan Krua Nuea Communit, and leader and representatives from the community of 15 people.

\section{B. Research Instruments}

1. Development of educational processes of a non-formal school system to raise awareness of supportive coexistence in urban communities. The research instruments were (1) a basic record containing the location of the community and the establishment of houses, the history of the community from the beginning to the present, population and economic characteristics of the community, community environment learning resources in the community, and the condition of problems arising in the community. Does the community have a learning center? Does the community have any quarrels or conflicts? Do household people participate in public activities for the benefit of the community? Whether the community has a community plan and whether the community plan has been implemented or not. (2)
Community survey, looks like a checklist of general information about the community, public service in the community, (3) Semi-structured interviews to obtain information on conditions, problems, causes, obstacles, and needs of supportive coexistence in urban communities; and (4) Rating scale questionnaires to assess standardized activities.

2. The presentation of practices in raising awareness of a supportive coexistence in urban communities through nonschool education processes. The research tools were openended critiques, allowing respondents to express their opinions freely.

\section{Data analysis}

The researcher performed the data analysis as follows:

1. Analyze the basic information of the community by classifying the data and presenting it in descriptive writing.

2. Analyze qualitative data from interviews by using content analysis.

3. The questionnaires were analyzed from the activities using mean and standard deviation.

4. Analyze data from focus group discussion by using content analysis

It is open-ended for respondents to express their opinions freely.

\section{Research findings}

1. Process of education non-formal school system to raise awareness of supportive coexistence in urban communities is divided into 5 steps: 1) problem perception, problem analysis of the community; 2) Reasons for coexistence in the community building a mutual learning agreement and defining learning activities to comply with the agreement, 3) Action, learning through hands-on actions, 4) summing up results, including summarizing the results of the activities, and 5) reflecting on the review such as the completion of the activities.

2. The results of the activities to raise awareness of a supportive coexistence in urban communities found that the participants showed good interest and cooperation in doing activities. The overall satisfaction was at the highest level, the mean value was 4.79. Overall, it is at a high level and the average was 2.92. Results of the AAR (After Action Review) review of post-work learning activities on organizing awareness-raising activities in a supportive coexistence in urban communities found that what we thought was doing well, able to carry out activities to achieve the goals that have been set, and everyone in the community attaches great importance to participating. Factors that contribute to doing well include planning meetings and prepared in advance and receiving cooperation from people in the community as well. Problems and obstacles include the participants are not diverse and the days spent doing too little activity. The solution is to organize activities should not be specific, just on holidays, may be scheduled to organize all important activities of the government, holy day, or an important day of the community and suggestions for improvement and development, including determining the community development activities is another main activity of the 
community. In addition, the community will benefit directly, and indirect benefits will be attractive to those who want to visit the community, it will bring income of the people in the community.

3. Guidelines for raising awareness of supportive coexistence in urban communities through non-formal education processes. This is the result of a participatory Action Research area in Ban Krua Nuea community, Ratchathewi District, Bangkok, and brought to the meeting with stakeholders, consisting of experts' religious leader, head of community. Development and Social Welfare as well as representatives from the community by using focus group discussion and summarizing the results from the group discussion, it is a practice to raise awareness of supportive coexistence in urban communities through nonschool education processes. To be used as a guideline or as information to support the community and organization of the network can be used. Found that consists of 8 or 8 principles, consisting of 1) "Participation", including participation in joint thinking and together to do and create together. 2) "Happiness", which is to participate in activities willingly and happy to join activities. 3) "Learning" is to learn yourself, learn others, learn community as well as learning to live together in society. 4) "Conservation" is to love and goodwill for each other, love and take care of people in the community and maintain the traditions and culture of the community to be persistent. 5) "Creative" to think creative activities and known to solve problems to develop communities to be progressive and sustainable. 6) "Coordination", including cooperation and have unity. 7) "Acceptation" is to accept and each each other, and 8) "Knowledge" means knowing your role and duty, knowing traditions, laws, and knowing the changes of the world.

\section{Discussions}

1. Fundamental beliefs of non-formal education process to raise awareness of the coexistence in urban communities give importance to the beliefs of people in the community who can learn to transform themselves to lead to a supportive coexistence in the community. It is consistent with the philosophy of non-formal education that is humanism and emphasizes humanity, recognize the differences between the individuals, accept the difference human development is therefore focused on individual development. Therefore, it must take into account the needs of the person and accept the knowledge and experience of the person which will be part of the learning process in which people in the community will see the changes themselves by analyzing the problems that arise in the community together. When encountering a problem, they will help each other learn to solve it leading to learning for changing oneself and the community. As a result, the self has been continuously developed, and the community has been developed to lead to a supportive coexistence.

2. Process of education in non-formal school system to raise awareness of a supportive coexistence in urban communities, as Sumalee Sangsri (2002) [12] and Sombat Suwanphitak (2000) [13] explained the principles and concepts comprising: 1) Building understanding for villagers to become aware of the problem and see the benefits and values for self-change. 2) Cooperation among villagers to jointly solve problems with steps. 3) Villagers can learn by themselves when what will be learned corresponds to the background community social context. 4) The learning of the villagers must be consistent and connected with the way of life and respond to the problems of the community, as mentioned in the principles of nonschool education management must be related to operating conditions. For the content of activities and curriculum of non-formal educational activities, it should be flexible and varied. In addition, it should have many types of activities and many disciplines. The content of each subject of the curriculum should also be flexible to match the social conditions of each locality, and organize activities to blend in with lifestyle without being separated from life.

3. Principles used in the implementation of non-school education processes to raise awareness of supportive coexistence in urban communities. It is a principle to promote awareness of the community's problems that arise with themselves and the community and aims to evolve to change for the better, consisting of 1) Raising awareness of problems arising and appreciating self-change in order to deal with problems. 2) Motivation for self-transformation Non-formal education management is a learning process in order for learners to develop their potential to be those who have a habit of constantly learning and pursuing learning. It should be able to live a normal life in the midst of the rapidly changing society. 3) The creation of learning to be consistent and connected with the way of life and responding to the problems of the community. This is the principle of learning to make people in the community see the value of learning that it can actually be used to solve problems in life. Where non-formal education integrates learning with lifestyle related to the problem state life and community environment [14]. This is related to [15] said that problem-based learning is the best way to develop $21 \mathrm{st}$ century skills. 4) Encourage learning to transform yourself from action.

4. In implementing the non-school education process to raise awareness of supportive coexistence in urban communities, since each area or each community has different contexts or conditions, there are factors and conditions for applying the non-formal education process to raise awareness of the supportive coexistence in urban communities. This is consistent with the findings of Sumalee Sangsri (2002) [16], and Archana Ratanaubol (2007) [17] as follows: 1) Having a working group or team with strength as mentioned in the objectives of non-formal education. The school said to promote democracy among the people. 2) The availability of places and resources to be used to learn. It will help make the learning process smooth and continuous. 3) Time availability of the participants the learning process. 4) Various communication and efficiency.

5. Guidelines for supportive coexistence in urban communities through non-formal education processes, from the research results, it was brought to the guidelines for a supportive coexistence in urban communities through nonschool education processes, including 8 items: 1) "Participation", namely participation in joint thinking, together to do and create together. 2) "Happiness", which is to participate in activities willingly and happy to join activities. 3) "Learning" is to learn yourself. Learn others Learn community as well as learning to live together in 
society. 4) "Conservation" is to love and goodwill for each other, love and take care of people in the community and maintain the traditions and culture of the community to be persistent, known to solve problems to develop communities to be progressive and sustainable. 6) "Coordination", including cooperation and have unity. 7) "Acceptation" is to accept and learn from each other, and 8) "knowledge" means knowing your role and duty, knowing traditions, laws, and knowing the changes of the world. The application of the guideline depends on the context of each area in which it will be applied accordingly [18]. This is in line with Wisani Silarakul (2001). [19] which identifies two components of the guideline. Which must be set in accordance with the goal and the guideline of the guideline must be consistent with the objectives for the implementation of the activities in that goal which the destination of an activity. There may be guidelines for a variety of actions. On the other hand, an approach may be for achieving more than one goal.

\section{Recommendations}

\section{A. Recommendations for the use of research results}

\section{Recommendations for Local Community}

1.1) Local communities can apply the educational process outside the school system to raise awareness of the supportive coexistence in urban communities and apply them to the context of the community. It can be applied in the application of learning activities. It can adjust or reduce the educational process outside the school system according to the context of each community.

1.2) Local communities should promote the participation of new generations. In learning activities by emphasizing the participation of a diverse group of people such as gender, age, occupation, religion, and should encourage and allow youth to use their energy and ideas. Brain power is to create according to his age and experience reflecting their views on the community or linking the community to external situations that they have or have experienced in. This will help diversify the learning process and more all around.

1.3) Local communities should provide opportunities for external agencies to participate in and support the community in the form of a learning activity development network. Third-party organizations may support in various forms such as finance, human resources, technology, communication, coordination and academia. Local authorities should work proactively by continuously seeking various external partnerships.

1.4) Local communities should create participatory communication channels for people in the community to use as a source for proposing needs. Exchange ideas Providing information through various channels, both personal media and technology media.

2. Recommendations to the development department

2.1) Ministry of Social Development and Human Security Bangkok Center for Non-formal and informal education as well as other communities and agencies developed indicators of complementary coexistence can be used to measure complementary coexistence in accordance with the nature and context of the target group to be assessed.

2.2 Responsible units or related units should focus on community development in respect of mutual acceptance and having a positive attitude towards individual differences to enable people in the community to be able to respect and accept diversity and to be able to live together happily with others.

\section{B. Recommendations for government policy}

1) The state should promote and support the building of national reconciliation and solidarity starting with promoting the community to have strength because if the community is strong enough to cope with various problems that can happen.

2) The states should implement non-formal education processes to raise awareness of the coexistence gained from this research, to define a frame guideline for promoting community coexistence, to provide agencies community development organizations can be applied or applied to the community appropriately and continue to be effective.

\section{B. Recommendations for the next research}

1) In the next research, knowledge Management may be used as a tool to acquire knowledge of the community.

2) There should be a practice guideline for raising awareness of supportive coexistence in urban communities through non-school education processes in order to know that it is appropriate and consistent with the situation of the local community other how far apart from Bangkok.

3) In further research, strong community indicators may be developed to be used in the process of increasing the ability community ability to coexist even more.

\section{References}

[1] D. Thawinphiphatkul. (1998). Urban processes and social change in developing countries, 2nd edition, Bangkok: Chulalongkorn University Press, 1998.

[2] J. Sujjanan. (2013). Education and Community Development in the 21st Century. Bangkok: Odeon Store, 2013.

[3] J. Sujjanan, Education and community development in the 21st century, Bangkok: Odeon Store, 2013.

[4] Study Center and Peace Development, Seminar to prevent and reduce conflicts in the community, Mahidol University, Nakhon Pathom, 2007.

[5] Office of Women's and Family Activities Ministry of Labor and Social Welfare, Analysis of the present Thai family, 2009, Retrieved from http:///www.womenfamily.go,th. 
[6] D. Thawinphiphatkul, Urban processes and social change in developing countries, 2nd edition, Bangkok: Chulalongkorn University Press, 1998.

[7] S. Wallipodom, Ban Krua community is Ban Bang Rachan, 2015, Retrieved from http: //www.lek-prapai.org/watch.php? Id $=940$.

[8] L. M. Guglielmino, Development of the self-directed learning readiness scale. Doctoral Dissertation, University of Georgia, 2008.

[9] S. Pornsiriphong, P. Usuparat and D. Kamnuwat, Initial study on Baan Khaek Nuea community. (Guest house, kitchen), Bangkok: Language and Culture Research Institute Mahidol University, 2007.

[10] Kemmis, S., \& McTaggart, R., The Action Research Planner, Victoria: Deakin University, 1990.

[11] M.S. Knowles, The Modern Practice of Adult Education, New York: The Adult Education, 1984.

[12] S. Srisang, Report of Non-formal Education for Lifelong Education in accordance with the National Education Act 1999, Bangkok: Good Print, 2002.

[13] S. Suwanpitak, New teaching techniques, Non-Formal Education Development Division Bangkok: Agricultural Cooperative Community of Thailand, 2000.

[14] W. Supanyo, Planning of teaching and learning in non-formal education, Unit 3 includes a series of teaching, training and development of non-formal educational materials, Department of Education Nonthaburi: Sukhothai Thammathirat Open University, 2002.

[15] C. Boonwattanakul, Guidelines for the management of non-formal and informal education for Thailand, Journal of Veridian E-Journal, Silpakorn University, Thai Language Edition, Vol. 9, Issue 3 (September - December 2016), 2016.

[16] S. Srisang, Report of Non-formal Education for Lifelong Education in accordance with the National Education Act 1999, Bangkok: Good Print, 2002.

[17] A. Rattanaubol, Organization of nonschool education program. Non-Formal Education Department, Faculty of Education, Chulalongkorn University, 2007.

[18] P. Coombs and M. Ahmed, Attacking Rural Poverty: How Non-Formal Education Can Help, Baltimore: The Johns Hopkins University Press, 1994.

[19] W. Silarakul, Informal education: from the concept of lifelong learning to practice, Bangkok: Center for the promotion of informal education Department of NonFormal Education, 2001. 